\title{
Phosphate Modification of Nano Titania and Its Effect on the Photodegradation of EDTA
}

\author{
Effat Iravani,* Sareh Ammari Allahyari and Meisam Torab-Mostaedi
}

Nuclear Science \& Technology Research Institute, P.O. Box 11365-8486, Tehran, Iran

\begin{abstract}
The surface of nano titania was phosphate modified and characterized by X-ray diffraction (XRD), attenuated total reflectance Fourier transform infrared spectroscopy (ATR-FTIR), energy dispersive X-ray analysis (EDX), and elemental analysis $(\mathrm{CHN})$ to show the existence of phosphate in the modified nano titania. The resultant phosphated nano titania was applied for photocatalytic degradation of ethylenediaminetetraacetic acid disodium salt (EDTA) in aqueous solution. The crystallite size and crystalline phase showed no considerable change after modification, hence photocatalytic effect improvement of phosphate modified nano titania compared with the pure nano titania could be probably due to the existence of phosphate groups on the surface. The changes of the initial $\mathrm{pH}$, photocatalyst dosage and EDTA concentration were tested in the degradation experiments. The pseudo-first-order kinetic model described the dynamic behavior for the photocatalytic degradation of EDTA using phosphate modified nano titania.
\end{abstract}

Keywords: photocatalytic degradation, phosphate modification, nano titania, EDTA, $o$-phosphorylethanolamine

\section{Introduction}

Ethylenediaminetetraacetic acid (EDTA) is mainly used as acid and sodium salt extensively, in several industrial and domestic applications like photo and paper industry. Using EDTA prevents sedimentation and tarnishing of metal surfaces and moreover intensifies the cleaning effect. Different products formulated to incorporate EDTA are distributed to a large number of outlets thus resulting in the disparate entry of EDTA in the aquatic environment. ${ }^{1}$ The total application volume of EDTA as an ingredient of household detergents, cosmetics, pharmaceutical and food is released via the household sewage without elimination in treatment plants. Unfortunately, volatilization from aqueous solution will not occur, due to its ionic properties and high solubility in water. The toxic effects of EDTA are considered to be related to metal deficiencies, especially a deficiency of zinc. It is well established that EDTA influences chromosome breakage by mutagenic agents, affects the inhibition of deoxyribonucleic acid (DNA) synthesis in primary cultures of mammalian cells and also leads to morphological changes of chromatin and chromosome structure in plant and animal cells. ${ }^{2}$ Removal of EDTA is not possible by biological treatment processes, ${ }^{3}$

*e-mail: eiravani@aeoi.org.ir using chlorine is not always efficient, ${ }^{4}$ and retention of the compound is hardly possible by activated carbon filters. ${ }^{5}$ Some advanced oxidation technologies for EDTA degradation have been established like ozonation, ${ }^{6} \mathrm{UV}$ with different oxidants, ${ }^{7,8}$ radiolysis ${ }^{9}$ and other combined techniques. ${ }^{8,10}$

The application of titania as a photocatalyst is limited due to its band gap of $3.2 \mathrm{eV} .{ }^{11}$ Several methods have been applied to improve the photocatalytic efficiency of titania, which include various modifications. A considerably smaller number of studies were devoted to phosphate modification of nano titania. Colón et al. ${ }^{12}$ found that phosphoric acid treatment led to decreasing the photoactivity of titania comparing with other oxoacids like nitric and sulfuric acid, while increasing the photocatalytic efficiency of titania was shown by Yu et al..$^{13}$ after phosphate modification. It was reported also that titania was modified with some anions like sulfate, tungstate and phosphate and used as supports for several solid catalysts. ${ }^{14,15}$ It was shown that post-treatment with phosphoric acid led to improve the thermal stability and acidity of mesoporous materials ${ }^{16,17}$ and zirconia. ${ }^{11}$

This paper describes the photocatalytic degradation of EDTA in the aqueous solution using phosphate modified nano titania with the final aim of establishing the best degradation conditions (optimized $\mathrm{pH}$, photocatalytic 
dosage, and initial concentration of EDTA) in terms of the highest degradation amount and lowest needed time.

\section{Experimental}

Materials

Nano titania, P-25 $\left(\mathrm{TiO}_{2}\right)$, with a purity of $99.5 \%(80 \%$ anatase, $20 \%$ rutile, $21 \mathrm{~nm}$ average particle size) was purchased from Evonik, Germany, and used as obtained for surface modification. $o$-Phosphorylethanolamine (OP) was purchased from Merck, Germany, with a purity of $98 \%$ and purified through recrystallization from distilled water before using. Ethylenediaminetetraacetic acid disodium salt dihydrate (EDTA) was purchased from Aldrich (Sigma grade, USA) and used without further purification. Copper(II) sulfate $\left(\mathrm{CuSO}_{4} .5 \mathrm{H}_{2} \mathrm{O}, \geq 98 \%\right)$ and indicator grade 1-(2 pyridylazo)-2-naphtol were obtained from Aldrich. Nitric acid (65\%) and sodium hydroxide (99\%) were purchased from Merck, Germany.

\section{Methods}

The sonication of the samples were performed with an Ultrawave sonicator (30 kHz). A calibrated Inolab pH meter was used to measure the $\mathrm{pH}$ of the samples. Thermal treatment was performed using Flli MANFREDI furnace. Attenuated total reflectance Fourier transform infrared (ATR-FTIR) spectra were recorded on a Bruker Tensor 27 ATR-FTIR spectrometer equipped with a ZnSe single crystal. The X-ray powder diffraction (XRD) patterns were recorded with a STOE STADI-MP diffractometer $(40 \mathrm{kV}$, $30 \mathrm{~mA}$ ) and equipped with a $\mathrm{Cu} \mathrm{K} \alpha$ radiation source $(\lambda=1.5418 \AA)$. Energy dispersive X-ray analysis (EDX) and elemental analysis (CHN) were performed on a REM CamScan-4DV and varioMICRO CHNS respectively. The amount of EDTA in the aqueous solution was determined titrimetrically against standard $\mathrm{Cu}^{2+}$ using 1-(2 pyridylazo)2-naphtol as indicator. ${ }^{18} \mathrm{~A}$ Metrohm 765 Dosimat was used to perform titration of the samples.

\section{Modification of nano titania}

Nano titania $\left(\mathrm{TiO}_{2}\right)$ was reacted with $o$-phosphorylethanolamine (OP) according to our previous work ${ }^{19}$ as follows. Nano titania was added in a round bottomed flask containing $50 \mathrm{~mL}$ of $0.01 \mathrm{~mol} \mathrm{~L}^{-1}$ of OP with a mole ratio of $\mathrm{TiO}_{2} / \mathrm{OP}: 10 / 1$ and stirred with a magnetic stirrer for $24 \mathrm{~h}$ at ambient temperature. Afterwards the powders were filtered and washed with water and ethanol and then eluted in a Soxhlet extractor with water for $24 \mathrm{~h}$. The product was then dried in an oven at $120{ }^{\circ} \mathrm{C}$ for $24 \mathrm{~h}$. The filtered powder $\left(\mathrm{TiO}_{2}-\mathrm{OP}\right)$ was washed with ethanol and then calcined at $400{ }^{\circ} \mathrm{C}$ for $2 \mathrm{~h}$ with a heating rate of $10{ }^{\circ} \mathrm{C} \mathrm{min}^{-1}$. The calcined sample was washed with distilled water and ethanol, filtered, dried at $100{ }^{\circ} \mathrm{C}$, labeled as $\mathrm{P}-\mathrm{TiO}_{2}$ and was used as the photocatalyst in the performed experiments.

\section{Design of photoreactor}

The photoreactor was a cuboid type, with dimensions of $45 \times 8 \times 10 \mathrm{~cm}$ containing two glass reaction vessels separated by a glass divider with a capacity of about $1000 \mathrm{~mL}$ (Figure S1). The photoreactor was equipped with a $15 \mathrm{~W}$ UV lamp with a length of $40 \mathrm{~cm}$ built into the quartz lamp housing. There were three ports for sampling, gas purging and outlet on the photoreactor cover for each vessel.

\section{General procedure of the photocatalytic experiments}

EDTA aqueous solutions with known concentrations between $250-1000 \mathrm{mg} \mathrm{L}^{-1}$ were prepared with distilled water. The certain amount of photocatalyst powder $\left(\mathrm{P}-\mathrm{TiO}_{2}\right)$ in the range of $0.125-0.75 \mathrm{~g}$ was added in $650 \mathrm{~mL}$ EDTA aqueous solution with the given concentration $\left(\mathrm{P}-\mathrm{TiO}_{2}\right.$ dosage in the range of about 0.19-1.15 $\left.\mathrm{g} \mathrm{L}^{-1}\right)$. When needed, the $\mathrm{pH}$ of solution was adjusted using nitric acid or sodium hydroxide solutions. The final mixture was sonicated prior to irradiation for 10 minutes to disperse it well. The concentration of EDTA after sonication was determined titrimetrically and used for the next calculations as the initial concentration. Then the solution was put into the reaction vessel. The photocatalyst was continuously dispersed in the aqueous solution by a magnetic stirrer. The air was purged in the dispersed solution during the irradiation. The experimental conditions for optimization treatments (18 experiments) were shown in Supplementary Information section (Table S1).

Samples were taken periodically for analysis every hour. The degradation efficiency $(\mathrm{d} \%)$ was calculated by applying equation 1:

$\mathrm{d} \%=\frac{\mathrm{C}_{0}-\mathrm{C}_{\mathrm{t}}}{\mathrm{C}_{0}} \times 100$

where $\mathrm{C}_{0}$ and $\mathrm{C}_{\mathrm{t}}$ are the initial and after $\mathrm{t}$ hours EDTA concentration, respectively. The degradation experiments were always repeated one more time after that calculated degradation efficiency showed no more change to verify the maximum amount of the degradation. 


\section{Results and Discussion}

\section{Phosphate modification of $\mathrm{TiO}_{2}$}

\section{Surface modifier selection}

Only a few studies have focused on photocatalytic activity of phosphate modified nano titania. Phosphate modification can be performed in situ or ex situ. In situ modification can affect some parameters like particle size, crystalline phase or stability simultaneously. ${ }^{20}$ So it will not be easy to focus just on the effect of phosphate groups on photocatalysis.

Phosphoric acid and different inorganic phosphates have been already used to modify nanoparticles. Depending on heating temperature and duration, phosphoric acid can dehydrate to form pyrophosphoric acid, metaphosphoric acid, or even polyphosphoric acids. ${ }^{21}$ The mentioned heating products could be probably formed as various titanium phosphates in the presence of various titanium salts as precursors. Among different titanium phosphates, titanium pyrophosphate is UV reflective which is able to suppress the photocatalytic activity. ${ }^{22}$ That is why that thermal treatment should be performed cautiously to avoid forming titanium pyrophosphate.

Raza et al..$^{23}$ have prepared phosphonate modified nano titania using organo phosphorus agent. Stability of the $\mathrm{P}-\mathrm{O}-\mathrm{Ti}$ bond against UV-irradiation was shown in this study, while the alkyl chain was degraded. It was assumed that a phosphate species was left on the surface after illumination. ${ }^{23}$

In this study, nano titania P-25 (Evonik) was modified ex situ using OP. It has been already shown that using long alkyl chain phosphates led to increase the van der Waals interactions between the alkyl chains, all-trans conformation of the chains, increasing the packing density and therefore more surface $\mathrm{OH}$ groups are replaced with phosphate groups ${ }^{24}$ which is not favorable to photocatalysis process (Figure S2). OP with chemical formula $(\mathrm{OH})_{2}(\mathrm{O}) \mathrm{PO}\left(\mathrm{CH}_{2}\right)_{2} \mathrm{NH}_{2}$ was chosen to modify $\mathrm{TiO}_{2}$ because of possessing short alkyl chain in order to assemble into a less dense structure.

\section{Characterization of $\mathrm{P}-\mathrm{TiO}_{2}$}

Non-bounded or weak-bounded OP and soluble titanium phosphate complexes were washed away in Soxhlet extraction, while the bounded OP remained on the surface of nano titania. According to the reported ${ }^{13} \mathrm{C}$-CP MAS NMR (cross-polarization magic angle spinning carbon-13 nuclear magnetic resonance) of $\mathrm{OP}-\mathrm{TiO}_{2}$ in our previous work, there was enough space for the alkyl chain $\left(-\mathrm{CH}_{2} \mathrm{CH}_{2} \mathrm{NH}_{2}\right)$ to be laid out parallel to the surface making hydrogen bond. ${ }^{19}$ This could be a proof to have a less dense structure. Accordingly it seemed to exist enough surface $\mathrm{OH}$ groups for photocatalysis.

Heating of $\mathrm{OP}-\mathrm{TiO}_{2}$ at $400{ }^{\circ} \mathrm{C}$ for $2 \mathrm{~h}$ led to decompose the organic rest and strengthen the interaction between the phosphate anions and the titanium sites. According to elemental analysis ( $\mathrm{CHN})$, the calcination product $\left(\mathrm{P}-\mathrm{TiO}_{2}\right)$ did not contain carbon or nitrogen any more, while EDX analysis of $\mathrm{P}_{-} \mathrm{TiO}_{2}$ showed that the calcined sample contained about 1.04 atom\% or 0.67 wt.\% phosphorus (Figure 1).

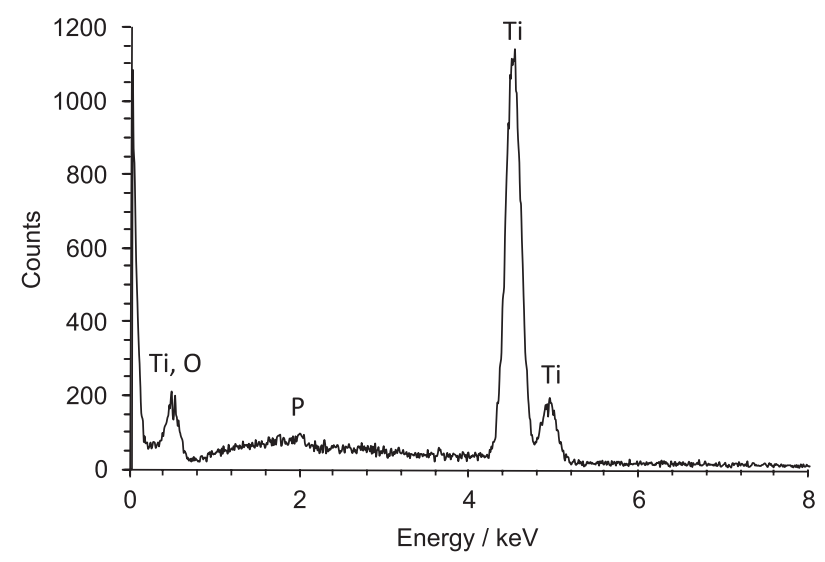

Figure 1. EDX analysis of $\mathrm{P}-\mathrm{TiO}_{2}$.

XRD spectra of pure $\mathrm{TiO}_{2}$ and the modified one before and after thermal treatment were displayed in Figure 2. There were no peaks of the organic agent to be recognized in the spectrum of $\mathrm{OP}-\mathrm{TiO}_{2}$. Surface functionalization in such a low amount could not affect the internal lattice parameters of a solid, or generate any diffraction peak. The crystalline phase after phosphate modification was a mixture of anatase and rutile as the pure nano $\mathrm{TiO}_{2}$ with no obvious change. The average crystallite size for $\mathrm{P}-\mathrm{TiO}_{2}$, estimated from the broadening of the diffraction peaks by Scherrer formula was about $24 \mathrm{~nm}$, also just about $3 \mathrm{~nm}$ more than the original $\mathrm{TiO}_{2}$ (reported by the producer to be about $21 \mathrm{~nm}$ ). As expected, the crystallite size and phase of nano $\mathrm{TiO}_{2}$ could not be influenced considerably during $e x$ situ phosphate modification. No considerable anatase-rutile transfer (ART) was observed after heating of $\mathrm{OP}-\mathrm{TiO}_{2}$ at 400 and even $600{ }^{\circ} \mathrm{C}$ for 2 hours. It seemed that phosphate could have stabilized the anatase phase up to $600{ }^{\circ} \mathrm{C}$. This type of effect has been also observed in sulfate ${ }^{25}$ and phosphate ${ }^{26}$ on $\mathrm{TiO}_{2}$ and $\alpha-\mathrm{Fe}(\mathrm{O}) \mathrm{OH}$, respectively.

Thermal treatment of $\mathrm{OP}-\mathrm{TiO}_{2}$ at higher temperature about $800{ }^{\circ} \mathrm{C}$ led to the formation of titanium pyrophosphate (TP) (Ref. code: 00-038-1468).

The evolution of ATR-FTIR spectra for phosphate modified nano titania before and after heating at $400{ }^{\circ} \mathrm{C}$ 


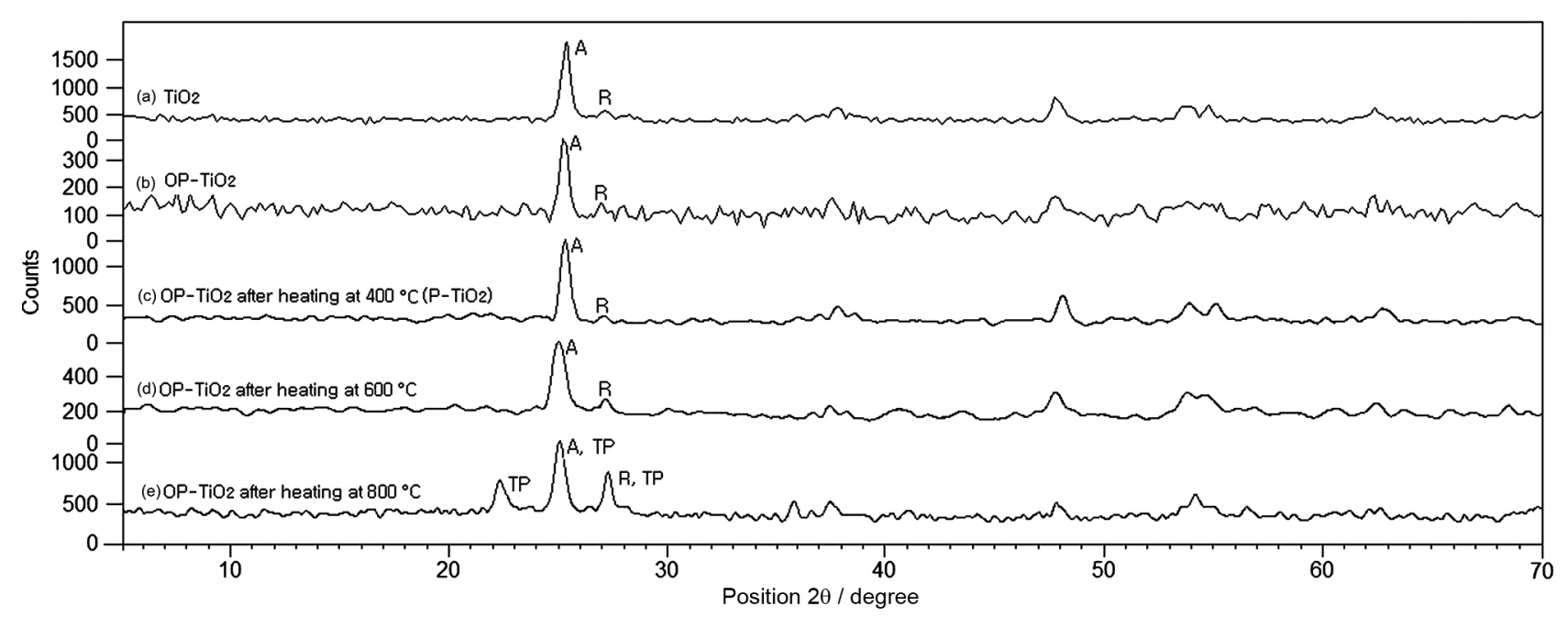

Figure 2. (a) $\mathrm{XRD}$ spectra of pure $\mathrm{TiO}_{2}$; (b) $\mathrm{OP}-\mathrm{TiO}_{2}$ before heating; and after heating at $400,600,800{ }^{\circ} \mathrm{C}$ (c, d, and e, respectively).

$\left(\mathrm{OP}-\mathrm{TiO}_{2}\right.$ and $\mathrm{P}-\mathrm{TiO}_{2}$, respectively) was shown in the Figure 3. The broad peaks around 3400 and $1600 \mathrm{~cm}^{-1}$ corresponded to the surface-adsorbed water and free hydroxyl groups. ${ }^{27}$ For $\mathrm{OP}-\mathrm{TiO}_{2}$, there were two sharp bands centered at 2933 and $2901 \mathrm{~cm}^{-1}$ related to symmetric and asymmetric stretching vibration of $-\mathrm{CH}_{2}-$ groups of $\mathrm{OP}$, which demonstrated the presence of organic material. The absence of these vibration bands in the spectrum of $\mathrm{P}_{-} \mathrm{TiO}_{2}$ suggested the removal of organic material after heating. However, an absorption band around $1090 \mathrm{~cm}^{-1}$ (characteristic frequency of $\left.\mathrm{PO}_{4}{ }^{3-}\right)^{28}$ appeared on the shoulder of -Ti-O-Ti vibration band in the spectrum of $\mathrm{P}-\mathrm{TiO}_{2}$, which revealed that phosphorus might have been incorporated on the surface of nano titania. The result of EDX analysis also supported this finding.



Figure 3. ATR-FTIR spectra of $\mathrm{OP}-\mathrm{TiO}_{2}$ and $\mathrm{P}-\mathrm{TiO}_{2}$.

\section{Photocatalytic experiments}

\section{Effect of surface modification}

EDTA (1000 $\left.\mathrm{mg} \mathrm{L}^{-1}\right)$ was slowly degraded under UV irradiation without any photocatalyst and the maximum amount of degradation was less than $40 \%$. Degradations under UV irradiation, in the presence of $\mathrm{TiO}_{2}$ or $\mathrm{P}_{-} \mathrm{TiO}_{2}$ as photocatalysts $\left(0.5 \mathrm{~g}, 0.77 \mathrm{~g} \mathrm{~L}^{-1}\right)$ and at natural $\mathrm{pH}$ of about 5.5 were performed much faster. Using $\mathrm{P}_{-} \mathrm{TiO}_{2}$ showed about twice more degradation of EDTA comparing to $\mathrm{TiO}_{2}$ (Figure S3). This meant that surface modification led to more degradation of EDTA under the same normal condition without any optimization. The maximum amount of degradation and the needed time were compared in Figure S4.

\section{Effect of initial $\mathrm{pH}$}

In order to check the $\mathrm{pH}$ changes, degradation of $650 \mathrm{~mL}$ EDTA $\left(1000 \mathrm{mg} \mathrm{L}^{-1}\right)$ in the presence of $\mathrm{P}_{-\mathrm{TiO}_{2}}$ $\left(0.5 \mathrm{~g}, 0.77 \mathrm{~g} \mathrm{~L}^{-1}\right)$ was performed first without adjusting the initial $\mathrm{pH}$ under $\mathrm{UV}$ irradiation. $\mathrm{pH}$ of the solution was measured periodically every hour. According to the results shown in Figure S6, pH of the solution was increased during the photocatalytic reaction from the initial $\mathrm{pH}$ (about 5.5) to about 9 , which could be probably a sign of producing basic intermediates.

The effect of the initial $\mathrm{pH}$ was investigated in the present study in the range of 4-9. Both kinetic and efficiency of degradation were decreased with $\mathrm{pH}$ increasing.

Accordingly acidic $\mathrm{pH}$ were more suitable for photocatalytic degradation of EDTA (Figure S7). An increase of $\mathrm{pH}$ about 1 unit led to decrease of achievable degradation level and increase the time needed. This observation was more considerable in basic range of $\mathrm{pH}$. Adjusting the initial $\mathrm{pH}$ of the solution about 4 (the optimized amount) led to about $30-50 \%$ less time and $12-16 \%$ more degradation efficiency of EDTA.

Generally in the $\mathrm{pH}$ range 3-8, the EDTA chemical species and its metal complexes are anion in the solution, ${ }^{29}$ 
therefore the adsorption on the surface could be probably performed in acidic $\mathrm{pH}$ better. To investigate this point, the dependence of EDTA adsorption $\left(650 \mathrm{~mL}, 1000 \mathrm{mg} \mathrm{L}^{-1}\right)$ on the $\mathrm{pH}$ of the solution (in the range of 3-9) in the presence of $\mathrm{P}_{-} \mathrm{TiO}_{2}(0.5 \mathrm{~g})$ was studied (Figure S5). According to the results, EDTA adsorption on the $\mathrm{P}-\mathrm{TiO}_{2}$ was faster at the acidic pHs compared with the basic pHs. It means, the fast kinetic of EDTA degradation using $\mathrm{P}_{-} \mathrm{TiO}_{2}$ under UV irradiation in the acidic $\mathrm{pH}$ compared with the neutral or basic $\mathrm{pHs}$ could be due to the increased EDTA adsorption.

\section{Effect of photocatalyst dosage}

Four experiments were established at optimized $\mathrm{pH} 4$ by using $\mathrm{P}^{-} \mathrm{TiO}_{2}$ with concentrations $0.19,0.38,0.77$ and $1.15 \mathrm{~g} \mathrm{~L}^{-1}$ to degrade EDTA solution (1000 $\mathrm{mg} \mathrm{g}^{-1}$ ). Increasing of the photocatalyst concentration to $1.15 \mathrm{~g} \mathrm{~L}^{-1} \mathrm{had}$ a negative effect on degradation efficiency compared with 0.38 and $0.77 \mathrm{~g} \mathrm{~L}^{-1}$. Increased light scattering and consequent reduction in light penetration through the solution could be mentioned as the reason (the effect of light masking by suspended excess catalyst particles).$^{30}$ Increasing the amount of photocatalyst from 0.38 to $0.77 \mathrm{~g} \mathrm{~L}^{-1}$ caused just about $2.24 \%$ more efficiency, which did not satisfy using twice more photocatalyst. To investigate this point more precisely, the experiment was repeated under the same condition using $0.54 \mathrm{~g} \mathrm{~L}^{-1}$ photocatalyst. Degradation efficiency increased with increase the amount of photocatalyst from 0.38 to $0.54 \mathrm{~g} \mathrm{~L}^{-1}$ and then decreased from 0.54 to $0.77 \mathrm{~g} \mathrm{~L}^{-1}$. Degradation efficiency and approximately needed time (experimental value) to degrade $50 \%$ of EDTA using three amounts of photocatalyst $\left(0.38,0.54,0.77 \mathrm{~g} \mathrm{~L}^{-1}\right)$ showed no considerable difference. According to the results showed in Figure 4, $0.38 \mathrm{~g} \mathrm{~L}^{-1}$ was reported as the optimized amount of $\mathrm{P}-\mathrm{TiO}_{2}$ to obtain the highest degradation efficiency and lowest half-life time.

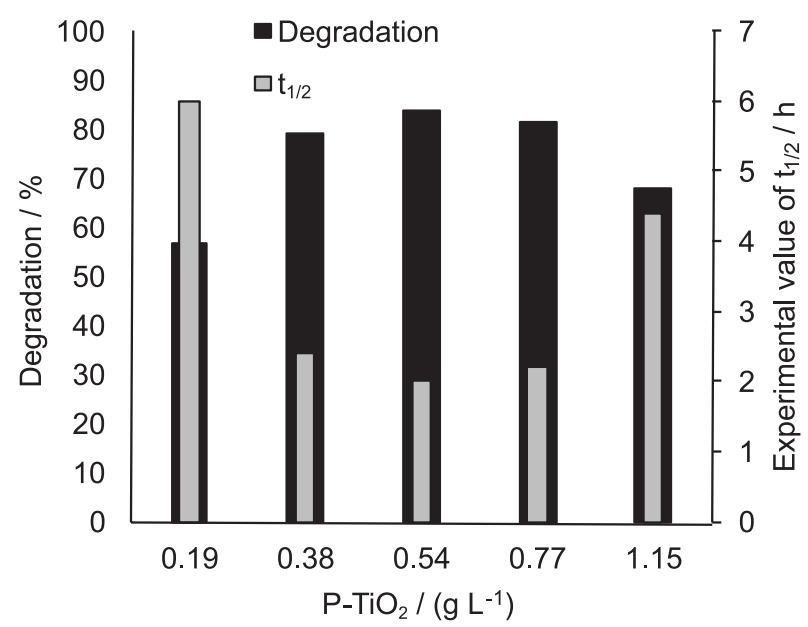

Figure 4. The effect of photocatalytic dosage on maximum amount of EDTA degradation and experimental half-life time.

\section{Effect of EDTA concentration}

Optimized amount of $\mathrm{P}^{-\mathrm{TiO}_{2}}\left(0.35 \mathrm{~g}, 0.38 \mathrm{~g} \mathrm{~L}^{-1}\right)$ was added to EDTA solutions at different initial concentrations ranging 250-1000 $\mathrm{mg} \mathrm{L}^{-1}$ at optimized $\mathrm{pH} 4$ and the resulted suspensions were irradiated under UV light. The normalized concentration profiles of EDTA revealed that the degradation was faster and the total conversion took place in less time, when the EDTA concentration was lower (Figure S8). In C was plotted versus time for various initial EDTA concentrations and shown in Figure S9.

The approximately linear decrease in the logarithm of the EDTA concentration with irradiation time was consistent with the pseudo first order kinetic expression (linear form) shown by equations 2 and 3:

$\ln \left(\frac{\mathrm{C}}{\mathrm{C}_{0}}\right)=-\mathrm{kt}$

$\ln \mathrm{C}=-\mathrm{kt}+\ln \mathrm{C}_{0}$

The apparent rate constants $(\mathrm{k})$ obtained from the least squares analyses (Figure S9) were decreased with increasing EDTA concentration (Table 1).

Langmuir-Hinshelwood kinetic is the most commonly used kinetic model for heterogeneous catalytic processes during the photodegradation of many organic contaminants in solution. ${ }^{31-34}$ Application of this model to an ideal batch reactor produces equation $4: 35$

Rate $=-\frac{\mathrm{dC}}{\mathrm{dt}}=\frac{\mathrm{K}_{\mathrm{r}} \mathrm{C}}{1+\mathrm{K}_{\mathrm{a}} \mathrm{C}+\sum \mathrm{K}_{\mathrm{i}} \mathrm{C}_{\mathrm{i}}}$

where $\mathrm{C}$ represents the solute concentration $\left(\mathrm{mg} \mathrm{L}^{-1}\right), \mathrm{K}_{\mathrm{r}}$ and $\mathrm{K}_{\mathrm{a}}$ are constants related to the reaction rate $\left(\mathrm{min}^{-1}\right)$ and adsorption coefficient $\left(\mathrm{L} \mathrm{mg}^{-1}\right)$, respectively, and $\Sigma \mathrm{K}_{\mathrm{i}} \mathrm{C}_{\mathrm{i}}$ is absorption term for all organic intermediate products. Considering $\mathrm{t}=0, \mathrm{C}=\mathrm{C}_{0}$ and the term for intermediate organic products $\Sigma \mathrm{K}_{\mathrm{i}} \mathrm{C}_{\mathrm{i}}=0$, then the equation 4 reduces to expression:

Rate $=-\frac{\mathrm{dC}}{\mathrm{dt}}=\frac{\mathrm{K}_{\mathrm{r}} \mathrm{C}}{1+\mathrm{K}_{\mathrm{a}} \mathrm{C}}$

The integral of equation 4 at $\mathrm{C}=\mathrm{C}_{0} / 2$ yields:

$\mathrm{t}_{1 / 2}=\frac{\mathrm{K}_{\mathrm{a}}}{\mathrm{K}_{\mathrm{r}}}\left(\mathrm{C}_{0} / 2\right)+\frac{0.693}{\mathrm{~K}_{\mathrm{r}}}$

Considering the pseudo first order kinetic according to equation 3, the half-life time of EDTA degradation for initial concentrations were calculated from least square 
Table 1. Pseudo-first order rate constants and $t_{1 / 2}$ values (experimental and calculated) for different initial concentrations of EDTA

\begin{tabular}{lccccc}
\hline Concentration $^{\mathrm{a}} /\left(\mathrm{mg} \mathrm{L}^{-1}\right)$ & $\mathrm{k}^{\mathrm{b}} / \mathrm{min}^{-1}$ & $\mathrm{R}^{\mathrm{b}}$ & Calculated $^{\mathrm{c}} \mathrm{t}_{1 / 2} / \min$ & Experimental $_{1 / 2} / \mathrm{min}$ & Initial reaction rate $^{\mathrm{d}} /\left(\mathrm{mg} \mathrm{L}^{-1} \mathrm{~min}^{-1}\right)$ \\
\hline 250 & 0.017 & 0.989 & 40 & 42 & 3.33 \\
500 & 0.009 & 0.9916 & 75 & 81 & 3.67 \\
750 & 0.007 & 0.9938 & 95 & 101 & 3.82 \\
1000 & 0.005 & 0.9946 & 130 & 139 & 3.90 \\
\hline
\end{tabular}

${ }^{a}$ Titrimetrically determined concentrations after 10 minutes sonication were used as the initial concentrations; ${ }^{\mathrm{b}, \mathrm{c}, \mathrm{d}}$ calculated using equations 3,6 and 5 , respectively.

analysis. If the rate of EDTA photocatalytic degradation follows the Langmuir isotherm equation model, plotting half-life time against $\mathrm{C}_{0} / 2$ according to equation 6 should yield a straight line with slope $\mathrm{K}_{\mathrm{a}} / \mathrm{K}_{\mathrm{r}}$ and intercept $0.693 / \mathrm{K}_{\mathrm{r}}$. The plot is linear (Figure 5), meaning that the reaction occurred on the surface. The values of $K_{a}$ and $K_{r}$ are $0.0154 \mathrm{~L} \mathrm{mg}^{-1}$ and $0.0641 \mathrm{~min}^{-1}$, respectively.

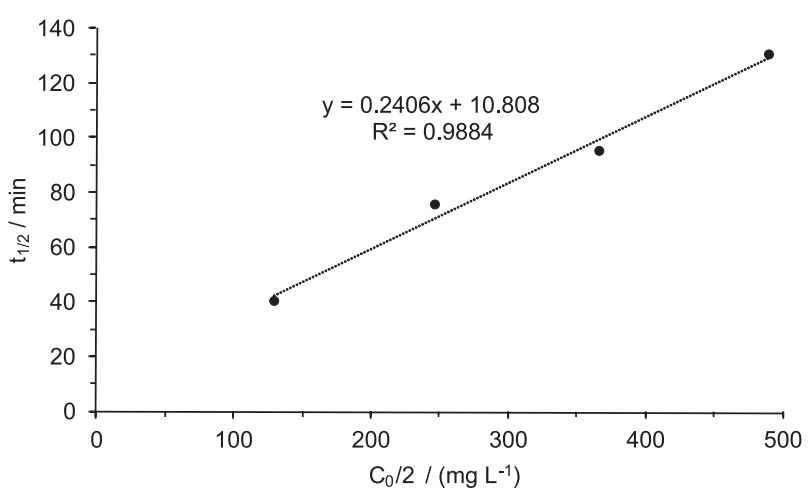

Figure 5. The plot of $\mathrm{t}_{1 / 2} v s$. $\mathrm{C}_{0} / 2$ values for different initial concentrations of EDTA.

Table 1 also showed the experimental and calculated $\mathrm{t}_{1 / 2}$ values obtained when $C / C_{0}=1 / 2$. The deviation between the experimental and calculated $t_{1 / 2}$ is greatest at higher EDTA concentrations, which could be ascribed to the induction period necessary to obtain equilibrium. ${ }^{36}$ The rates constants were $0.017,0.009,0.007$, and $0.005 \mathrm{~min}^{-1}$ in ascending concentration order, respectively.

The effect of surface modification with phosphate on photocatalysis

There were no considerable changes in crystallite size and phase after in situ phosphate modification of $\mathrm{TiO}_{2}$ indicating that the improvement of photocatalytic activity of $\mathrm{P}-\mathrm{TiO}_{2}$ can be attributed to the surface-bound phosphate anions. It has been already reported that the point of zero zeta potential of the nano titania particles are shifted to lower $\mathrm{pH}$ value in the presence of phosphate anion which indicates the accumulation of negative charges on the surface of nano titania. ${ }^{37}$ It seems, a negative electrostatic field could be formed in the surface layer of the nano titania due to the existence of negatively charged phosphate anions. During the photocatalysis process, the separation of electrons and holes could be promoted by this negative electrostatic field and as a result the charge recombination on phosphate modified nano titania is suppressed compared with the pure nano titania. When modified nano titania is irradiated by $\mathrm{UV}$, electron is excited from valance band to the conduction band leaving a positive hole in the valence band. Another positive effect of the negative electrostatic field could be probably to draw the positive hole to the interface. Strong interactions can be formed between phosphate and $\mathrm{H}_{2} \mathrm{O}$ through hydrogen bonding. Phosphate, known as a good anchor group, can accomplish efficient electron transfer between the nano titania and chromophore in the photoelectron cell. ${ }^{38,39}$ Apparently phosphate modification of the surface can promote the charge transfer between the hole and $\mathrm{H}_{2} \mathrm{O}$ to form free hydroxyl radical. In addition, the replacement of the adsorbed hydroxyl groups on the surface by phosphate anions can also inhibit the formation of surface-adsorbed hydroxyl radical. However it seems that the positive effects (inhibition of the charge recombination, drawing the holes to the interface and promotion of free hydroxyl radicals via facilitation of charge transfer between holes and $\mathrm{H}_{2} \mathrm{O}$ ) play more important role than the negative effect of replacement of some surface hydroxyl groups by phosphate anion (Figure 6). It should also be noted that the transfer of conduction band electron can also be possibly influenced by the phosphate modification.

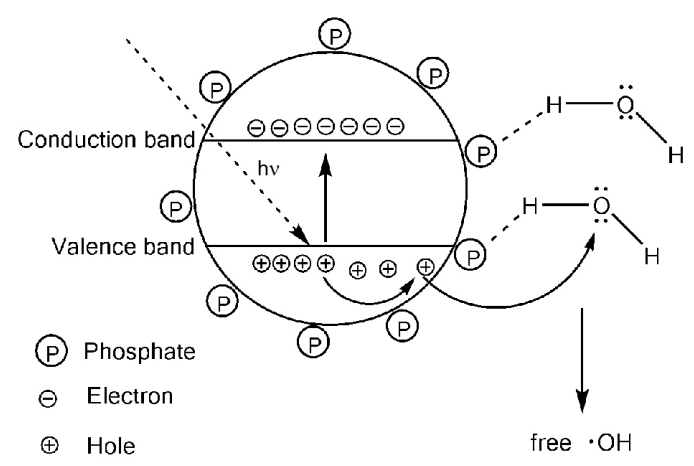

Figure 6. Schematic illustration of photo-generation of charge carriers in $\mathrm{P}-\mathrm{TiO}_{2}$. Phosphate modification of the $\mathrm{TiO}_{2}$ surface leads to inhibition of charge recombination, draws the holes to the interface and promotes free hydroxyl radicals generation via facilitation of charge transfer between holes and $\mathrm{H}_{2} \mathrm{O}$. 
Phosphate modification of the $\mathrm{TiO}_{2}$ surface leads to inhibition of charge recombination, draws the holes to the interface and promotes free hydroxyl radicals generation via facilitation of charge transfer between holes and $\mathrm{H}_{2} \mathrm{O}$.

\section{Conclusions}

Surface modification of $\mathrm{TiO}_{2}$ was performed with OP. After calcination at $400{ }^{\circ} \mathrm{C}$ for 2 hours, the organic rest was removed according to the result of CHN, ATR-FTIR analyses and phosphate groups remained on the surface of nano titania. The photocatalytic activity of the modified nano titania was investigated on the degradation of EDTA in aqueous solution. Both efficiency and kinetic of EDTA degradation showed considerable performance in acidic $\mathrm{pH}$ probably due to better EDTA adsorption. The rate of photocatalytic degradation of EDTA approximated pseudo-first-order kinetics. The optimum amount of photocatalyst was $0.35 \mathrm{~g}\left(0.38 \mathrm{~g} \mathrm{~L}^{-1}\right)$ to degrade $650 \mathrm{~mL}$ EDTA $1000 \mathrm{mg} \mathrm{L}^{-1}$. The reaction rate constant decreased as the EDTA concentration increased from 250 to $1000 \mathrm{mg} \mathrm{L}^{-1}$. The presence of phosphate groups on the nano titania surface was seemed to be sufficient to prevent matter transport delaying, inhibition of charge recombination, drawing the holes to the interface and the promotion of free hydroxyl radicals via facilitation of charge transfer between holes and $\mathrm{H}_{2} \mathrm{O}$. According to the proposed mechanism, both the surface hole and the free hydroxyl radical generation might be enhanced after the phosphate modification.

\section{Supplementary Information}

Supplementary data (photoreactor design and the effects of some parameters on the EDTA degradation in form of Excel graphs) are available free of charge at http://jbcs.sbq.org.br as PDF file.

\section{Acknowledgments}

The authors are grateful to Leila Irannejad for great technical support.

\section{References}

1. EDETIC ACID; Summary Risk Assessment Report; Institute for Health and Consumer Protection; European Chemicals Bureau, 2004, p. 7.

2. Heindorff, K.; Aurich, O.; Michaelis, A.; Rieger, R.; Mutat. Res. 1983, 115, 149.

3. Hinck, M. L.; Ferguson, J.; Puhaakka, J.; Water Sci. Technol. 1997, 35, 25.
4. Brauch, H. J.; Schullerer, S.; Vom Wasser 1987, 69, 155.

5. Schullerer, S.; Brauch, H. J.; Vom Wasser 1989, 72, 23.

6. Korhonen, M. S.; Metsarinne, S. E.; Tuhkanen, T. A.; Ozone: Sci. Eng. 2000, 22, 279.

7. Tucker, M. D.; Barton, L. L.; Thomson, B. M.; Wagener, B. M.; Aragon, A.; Waste Manage. 1999, 19, 477.

8. Rodriguez, J.; Mutis, A.; Yeber, M. C.; Freer, J.; Baeza, J.; Mansilla, H. D.; Water Sci. Technol. 1999, 40, 267.

9. Krapfenbauer, K.; Getoff, N.; Radiat. Phys. Chem. 1999, 55, 385.

10. Kagaya, S.; Bitoh, Y.; Hasegawa, K.; Chem. Lett. 1997, $2,155$.

11. Goswami, P.; Nath Ganguli, J.; Bull. Mater. Sci. 2012, 35, 889.

12. Colón, G.; Sánchez-Espana, J. M.; Hidalgo, M. C.; Navío, J. A.; J. Photochem. Photobiol., A 2006, 179, 20.

13. Yu, J. C.; Zhang, L.; Zhang, Z.; Zhao, J.; Chem. Mater. 2003, $15,2280$.

14. Hino, M.; Arata, K. J.; J. Chem. Soc., Chem. Commun. 1980, 851.

15. Larsen, G.; Loreto, F.; Nasity, M.; Petkovu, L. M.; Shobe, D. S.; J. Catal. 1996, 164, 246.

16. Ciesla, U.; Schacht, S.; Stucky, G. D.; Unger, K. K.; Schuth, F.; Angew. Chem., Int. Ed. Engl. 1996, 35, 541.

17. Chen, H. R.; Shi, J. I.; Hua, Z. H. I.; Yuan, L. I.; Yan, D. S.; Mater. Lett. 2001, 51, 187.

18. D1767-89: Standard Test Method for Ethylen Diamine Tetraacetate (EDTA) in Soaps or Synthetic Detergents, 2003.

19. Iravani, E.; Allahyari, S. A.; Shojaei, Z.; Torab-Mostaedi, M.; J. Braz. Chem. Soc. 2015, 26, 1608.

20. Zhao, D.; Chen, C.; Wang, Y.; Li, H.; Ma, W.; Zang, L.; Zhao, J.; J. Phys. Chem. C 2008, 112, 5993.

21. Holleman, F.; Wieberg, E.; Wieberg, N.; Lehrbuch der Anorganischen Chemie, $101^{\text {st }}$ ed.; de Gruyter: Berlin, New York, 1995.

22. Onoda, H.; Yamaguchi, T.; Toyama, T.; Phosphorus Res. Bull. 2013, $28,1$.

23. Raza, M.; Bachinger, A.; Zahn, N.; Kickelbick, G.; Materials 2014, 7, 2890.

24. Pori, D. M.; Venkataraman, N. V.; Tosatti, S. G. P.; Durmaz, F.; Spencer, N. D.; Zuercher, S.; Langmuir 2007, 23, 8053.

25. Zhao, B. Y.; Xu, X. P.; Ma, H. R.; Gao, J. M.; Sun, D. H.; Wang, R. R.; Tang, Y. A. N.; Acta Phys.-Chim. Sin. 1993, 9, 8.

26. Kandori, K.; Uchida, S.; Kataoka, S.; Ishikawa, T. J.; Mater. Sci. 1992, 27, 719.

27. Ding, Z.; Lu, G. O.; Greenfield, P. F.; J. Phys. Chem. B 2000 , $104,4815$.

28. Bhaumik, A.; Inagaki, S.; J. Am. Chem. Soc. 2001, 123, 691.

29. Sugiyama, T.; Dabwan, A. H. A.; Katsumata, H.; Suzuki, T.; Kaneco, S.; Open J. Inorg. Non-Met. Mater. 2014, 4, 28.

30. Parra, S.; Stanca, S. E.; Guasaquillo, I.; Ravindranathan Thampi, K.; Appl. Catal., B 2004, 51, 107. 
31. Kabra, K.; Chaudhary, R.; Sawhney, R. L.; Ind. Eng. Chem. Res. 2004, 43, 7683.

32. Moctezuma, E.; González, R.; Zamarripa, H.; Palestino, G.; Oros, S.; J. Environ. Eng. Manage. 2006, 16, 343.

33. Dalrymple, O.; Yeh, D.; Trotz, M. J.; J. Chem. Technol. Biotechnol. 2007, 82, 121.

34. Leyva, E.; Montalvo, C.; Moctezuma, E.; Leyva, S.; J. Ceram. Process. Res. 2008, 9, 455.

35. Aguilar, C. A.; Montalvo, C.; Ceron, J. G.; Moctezuma, E.; Int. J. Environ. Res. 2011, 5, 1071.
36. Matthews, R. W.; J. Catal. 1988, 111, 264.

37. Nelson, B. P.; Candal, R.; Corn, R. M.; Anderson, M. A.; Langmuir 2000, 16, 6094.

38. Bae, E.; Choi, W.; Park, J.; Shin, H. S.; Kim, S. B.; Lee, J. S.; J. Phys. Chem. B 2004, 108, 14093.

39. Ernstorfer, R.; Gundlach, L.; Felber, S.; Storck, W.; Eichberger, R.; Willig, F.; J. Phys. Chem. B 2006, 110, 25383.

Submitted: September 30, 2015 Published online: February 18, 2016 